\title{
A Novel Hybrid Compensation Method Reducing the Effects of Distorted Input Voltages in Matrix Converters
}

\author{
Hulusi Karaca ${ }^{1, *}$, Ramazan Akkaya ${ }^{2}$ \\ ${ }^{I}$ Department of Electrical and Electronics Engineering, Technology Faculty, Selcuk University, \\ 42079 Konya, Turkey \\ ${ }^{2}$ Department of Electrical and Electronics Engineering, Engineering and Nature Sciences Faculty, \\ Konya Technical University, \\ 42130 Konya, Turkey \\ hkaraca@selcuk.edu.tr
}

\begin{abstract}
Matrix converters have the most compact and efficient AC-AC converter structure due to the lack of the DC intermediate components. The matrix converter makes a single-stage conversion directly connecting any terminal of voltage source to any terminal of load. This outstanding feature leads to some problems that must be overcome under the distorted input voltage conditions. A matrix converter has low immunity to power source disturbances, because it has no DC intermediate circuit. Any disturbance in the power source creates a negative effect on the load of the matrix converter and on the current drawn from the source. In this study, a novel compensation method, which provides immunity against input voltage disturbances, is suggested for the matrix converter. The suggested method has a hybrid structure, which includes both feedforward and fuzzy logic controller based feedback methods. The effectiveness and accuracy of the suggested new hybrid compensation approach are proved by the various results obtained.
\end{abstract}

Index Terms-Matrix converter; Distorted input voltages; AC-AC converters; Hybrid compensation.

\section{INTRODUCTION}

The matrix converter (MC) is an AC-AC power converter making only single-conversions. Since there is no DC link as in traditional converters, the $\mathrm{MC}$ has a structure occupying less space than indirect AC-AC converters. The matrix converter presents a number of outstanding features, including the generation of output voltage with the desirable frequency and amplitude, sinusoidal output and input currents, unity displacement factor regardless of the load, compact design, and four-quadrant operation [1].

However, pure sinusoidal output and input currents can be obtained only under the supposition that the voltage source is pure sinusoidal and balanced. In practice, MC may be exposed to abnormal input voltages, including an unbalanced one, a surge or a harmonic. The nonsinusoidal/abnormal input voltages adversely affect the load of the matrix converter. This situation may cause undesirable harmonics in the load current because there are

Manuscript received 15 February, 2019; accepted 22 September, 2019.

This research was funded by the Scientific Research Projects Coordinating Office of Selcuk University (SÜBAP). not any reactive components or any DC-link in the structure of MC. Therefore, although the MC has the abovementioned extraordinary characteristics, the attention it deserves has not yet been paid in the industry [2]. If these destructive impacts of abnormal input voltages are prevented, the interest in MC may increase further [3]. In the last decade, the endeavours of researchers have been devoted to the improvement of miscellaneous control and modulation techniques that can be applied to MCs [4]. In recent years, some control methods that decrease the impacts of distorted sources on output voltages, output currents, and input currents of the $\mathrm{MC}$ have been published.

In [5], a compensation method, which implements the load current's control, is introduced to decrease the negative impacts of distorted source voltages in the matrix converter. The closed loop control is provided by a fuzzy logic controller. In [6] and [7], a modified space vector modulation (SVM) method is described for MC in instances of abnormal input voltages, including unbalanced, harmonic, and surge. The instantaneous phase and magnitude of the input voltage vector are used to compute the phase angle of the input current and the voltage transfer function. In [8] and [9], the Z-source sparse matrix converters (ZSMCs) are proposed. A load and a source by means of a Z-source network without DC components are connected by ZSMC, even if it realizes a two-stage conversion. Thus, the disturbances in source voltage are directly reflected to the output of ZSMC. Therefore, the FLC based compensation method, which is first proposed in [3] and [5], is applied to compensate the negative influences of abnormal input voltages for the direct MC. In [10], an analysis is performed to enhance the current quality of the MC controlled by SVM feeding inductive loads. The analysis is based on obtaining the optimal use of zero vectors. So, a lower current ripple, a higher voltage transfer ratio (voltage-gain), and also a lower commutation quantities are ensured in the matrix converter. The behaviour of MC in regards to distorted input voltages is investigated in [11]. A method is proposed to minimize the input current harmonics caused by unbalanced input voltages. The three phase input voltages measured by voltage sensors are used in this technique. In [12], two 
modulation methods are introduced for the MC controlled by the SVM method in the case of an unbalanced source. In the first of the methods, the vector of input currents is regulated in the same phase with the vector of phase voltages. In the second method, the vector of input currents is regulated continuously around the direction of the phase voltage.

In [13], three modulation methods, which have positive, negative, and combined switching patterns for single-phase matrix converters are presented. Using these methods, sinusoidal output voltages are obtained and total harmonic distortions (THD) of output and input currents are reduced. In [14], a controller based on internal model control is presented in the case of abnormal input voltages for the MC, which feeds induction motor drives controlled with vector control. This method has the ability to set point tracking. In [15], a matrix converter with 4-leg topology is presented for use instead of the back-to-back converter. In [16], a 4-leg matrix converter is presented to feed the resonant control systems regulating the imbalanced or non-linear loads.

In this study, a hybrid compensation technique is suggested to reduce the unwanted results of abnormal input voltages in MCs. In the proposed technique, the measurements of three-phase supply voltages and threephase output currents by three voltage sensors and three current sensors are required. The suggested technique satisfactorily minimizes the negative effects of the distorted voltage sources both on the output and input side of MC. It improves both the THDs of the currents drawn from the source and the output performance of the MC. Several numerical outcomes are given to evidence the correctness of the novel hybrid compensation method.

\section{BASICS AND CONTROL STRATEGY OF MATRIX CONVERTER}

The MC converts AC energy at a fixed frequency and amplitude to AC energy at a variable frequency and amplitude [17]. It is composed of nine bidirectional power switches, which directly connect the output and input of the converter. These bidirectional switches are constructed by two anti-parallel fast diodes and two insulated-gate bipolar transistors (IGBT). Technically, the number of the input phases of the matrix converter has to be at least three, and the number of the output phases can be selected to be between one and infinity [3]. The fundamental topology of MC is coupling the 3-phase loads with the 3-phase input voltages without any DC intermediate components as illustrated in Fig. 1. The MC has the ability to adjust the output frequency limitlessly. It may produce output frequencies both bigger and smaller than that of the input. The output voltages of the MC are composed of segments of three input phase voltages at the switching period.

$S_{K j}$ are switches between phase $j$ of the output and the input phase $K$ of the MC for $K=A, B, C$ and $j=a, b, c$. The output voltage $v_{j N}$ is produced by switching properly the bidirectional power switches at high frequencies.

MC has to be controlled without the violation of the fundamental two rules. The first rule is that none of the switches between any two input phases must ever be switched-on at the same time to prevent a short-circuit. The second rule is that no load terminals should ever be opencircuited, because there is not a free-wheeling way for the current of the inductive load. If one of the output phases is open-circuited, the power switches are exposed to very high voltages [18]. These rules can be represented as follows:

$$
\left\{\begin{array}{l}
m_{A a^{(t)+m}} m_{B a}{ }^{(t)+m_{C a}}(t)=1, \\
m_{A b^{(t)+m_{B b}}}(t)+m_{C b}(t)=1, \\
m_{A c^{(t)+m_{B c}}}(t)+m_{C c}(t)=1 .
\end{array}\right.
$$

There are 512 different switching positions for the 3 phase to 3-phase MCs. There are only 27 different switching positions adhering to the mentioned rules [18].

The suitable switching functions for all of the power switches should be computed to achieve the sinusoidal load voltages at variable-amplitude and variable-frequency in the MC fed by the sinusoidal voltage source at fixed-amplitude and fixed-frequency.

In this study, $v_{K}$ is the input voltage of the converter. The output voltage being in accordance with the neutral point $n$ of the load is $v_{j n}$. The output voltage in accordance with the neutral point $N$ of the supply is $v_{j N}$. $i_{K}$ is the input current of the converter and $i_{j}$ is the output current of the converter. If the conduction times of the switches $S_{K j}$ and the sampling interval are respectively defined as $t_{K j}$ and $T_{s}$, the duty cycles of switches $S_{K j}$ may be expressed by (2)

$$
m_{K j}(t)=\frac{t_{K j}}{T_{s}} .
$$

Then, modulation matrix is represented as in (3)

$$
M(t)=\left[m_{K j}(t)\right]=\left\lfloor\begin{array}{lll}
m_{A a}(t) & m_{B a}(t) & m_{C a}(t) \\
m_{A b}(t) & m_{B b}(t) & m_{C b}(t) \\
m_{A c}(t) & m_{B c}(t) & m_{C c}(t)
\end{array}\right\rfloor .
$$

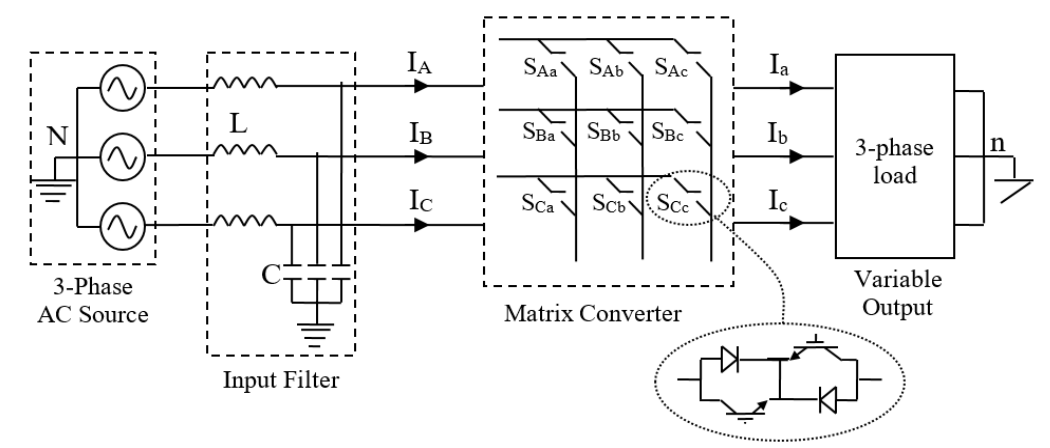

Fig. 1. Topology of $3 \times 3$ matrix converter. 
In normal circumstances, the 3-phase input voltages of the matrix converter can be denoted as in (4)

$$
v_{i}(t)=\left[v_{K}(t)\right]=V_{i m}\left[\begin{array}{l}
\cos \left(\omega_{i} t\right) \\
\cos \left(\omega_{i} t+2 \pi / 3\right) \\
\cos \left(\omega_{i} t+4 \pi / 3\right)
\end{array}\right] .
$$

Accordingly, the output voltage in accordance with the neutral point $N$ of the supply can be obtained as in (5)

$$
v_{o}(t)=\left\lfloor v_{j N}(t)\right\rfloor=[M(t)]\left[v_{K}(t)\right]
$$

Also, the input currents can be written as following

$$
\left[i_{K}(t)\right]=[M(t)]^{T}\left[i_{j}(t)\right]
$$

In this equation, $[M(t)]^{T}$ is the transpose of the modulation matrix.

The voltage transfer ratio (voltage-gain) was 0.5 in the first modulation method introduced by Venturini and Alesina [19]. The highest voltage-gain was achieved by injecting the $3^{\text {rd }}$ harmonics of the output and input to the goal load voltages in [20]. The injection of the third harmonics is realized as given in (7)

$$
\left.\left[v_{j N}(t)\right]=q V_{i m} \mid \begin{array}{l}
\cos \left(\omega_{o} t\right)-\frac{1}{6} \cos \left(3 \omega_{o} t\right)+\frac{1}{2 \sqrt{3}} \cos \left(3 \omega_{i} t\right) \\
\cos \left(\omega_{o} t+\frac{2 \pi}{3}\right)-\frac{1}{6} \cos \left(3 \omega_{o} t\right)+\frac{1}{2 \sqrt{3}} \cos \left(3 \omega_{i} t\right) \\
\cos \left(\omega_{o} t+\frac{4 \pi}{3}\right)-\frac{1}{6} \cos \left(3 \omega_{o} t\right)+\frac{1}{2 \sqrt{3}} \cos \left(3 \omega_{i} t\right)
\end{array}\right] .
$$

In this equation, $q$ is the voltage transfer ratio or voltage gain. The obtained maximum voltage-gain is $86.6 \%$ by using the injection of third harmonics. The injection of third harmonics to the goal load voltage does not affect the phase to phase voltages of load [21]. The targeted load voltages are equal to the average load voltages.

If it is desired to achieve the unity power factor in the input of the MC, the modulation index can be calculated by (8) [1]

$$
m_{K j}=\frac{1}{3}\left\lfloor 1+\frac{2 v_{K} v_{j}}{V_{i m}^{2}}+\frac{2 q}{3 q_{m}} \sin \left(\omega_{i} t+\beta_{K}\right) \sin \left(3 \omega_{i} t\right)\right\rfloor,
$$

where $\beta_{K}=0, \frac{2 \pi}{3}, \frac{4 \pi}{3}$.

So, the duty cycles of power switches can be computed as in (9)

$$
t_{K j}=T_{s}\left\lfloor\frac{1}{3}+\frac{2 v_{K} v_{j}}{3 V_{i m}^{2}}+\frac{2 q}{9 q_{m}} \sin \left(\omega_{i} t+\beta_{K}\right) \sin \left(3 \omega_{i} t\right)\right\rfloor .
$$

\section{PROPOSED HYBRID COMPENSATION METHOD}

The matrix converter is generally controlled by one of two modulation methods. They are the space vector modulation method and the Venturini modulation method.
Both of these methods presume that three-phase input voltages have pure-sinusoidal and balanced waveforms. Therefore, prearranged switching patterns are commonly used in the conventional control of the matrix converter. Additionally, the precalculated switching patterns of the power switches are saved into a table for specific frequency and/or amplitude values [3].

However, if matrix converters are controlled by using the prearranged switching patterns, the abnormal input voltages negatively influence both the output current and input current of the MC and the undesired harmonics occur on the input current and output current of MC due to the absence of DC intermediate components. So, if the input voltages are non-sinusoidal or unbalanced, it is not suitable to use the prearranged switching patterns. Hence, in this study, the duty cycles of switches are instantaneously computed, taking into account the disturbances on the output currents and input voltages.

In this work, a novel compensation method is presented for the matrix converter (Fig. 2), which provides immunity against input voltage disturbances. This novel method has a hybrid structure, which includes both the feedforward method and the FLC based feedback method [22]. While duty cycles for switches are instantaneously calculated, it takes into account both distortions of input voltages and that of output currents.

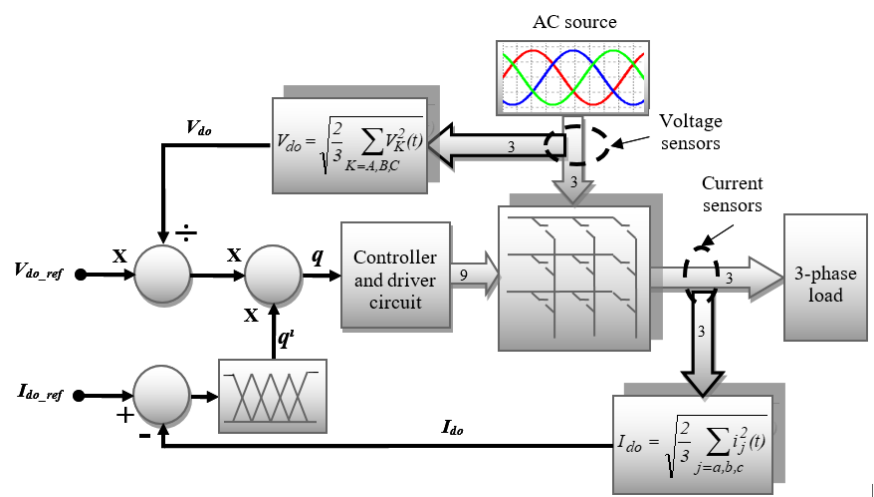

Fig. 2. Block diagram of hybrid compensation method for matrix converter. 
First, the output currents are gauged by three phase current sensors. Second, the output current space vector magnitude $\left(I_{d o}\right)$ is calculated at each sampling period according to (10) [3]

$$
I_{d o}=\sqrt{\frac{2}{3} \sum_{j=a, b, c} i_{j}^{2}(t)} .
$$

Then, the input voltages are measured by three phase voltage sensors. The virtual DC line voltage $\left(V_{d o}\right)$ is calculated at each sampling period according to equation (11)

$$
V_{d o}=\sqrt{\frac{2}{3} \sum_{K=A, B, C} V_{K}^{2}(t)} .
$$

If MC is fed by balanced and sinusoidal source voltages, the waveform of the current drawn by the load is sinusoidal too. Oscillation of the $V_{d o}$ with respect to time is stable due to the sinusoidal input voltages. Also, oscillation of the $I_{d o}$ with respect to time is stable owing to the sinusoidal output currents.

On the other hand, when MCs are fed by unbalanced or distorted source voltages, the waveforms of $V_{d o}$ and $I_{d o}$ are unstable with respect to time.

In accordance with this information, if $I_{d o}$ can be kept constantly under the non-sinusoidal input voltage conditions, the negative impacts of the distorted input voltages are not reflected in the output of the MC. In this study, a fuzzy logic controller based feedback system is used to achieve this. The instantaneous error of $I_{d o}$ in equation (12) and its change $\Delta e(k)$ in equation (13) is entered to the FLC as inputs. As a result, the FLC generates a non-fixed voltage-gain $\left(q^{l}\right)$ depending on the distortion of the output current:

$$
\begin{aligned}
& e(k)=\left\lfloor I_{d o}(k)-I_{d o \_r e f}(k)\right\rfloor \times \alpha, \\
& \Delta e(k)=\lfloor e(k)-e(k-l)\rfloor \times \beta,
\end{aligned}
$$

where $\alpha$ and $\beta$ are normalization factors and $k$ is the present sampling period. Actually, the fuzzy logic controller has generated the change of the voltage-gain " $\Delta q^{l}(k)$ ". The ultimate voltage-gain " $q^{l}(k)$ " generated by the FLC system is the sum of the variation and previous value of the voltagegain as given in (14)

$$
q^{l}(k)=q^{l}(k-1)+\Delta q^{i}(k)
$$

The FLC used in this work and its rule base was clearly explained in our another paper [3].

In the feedforward system, firstly, the instantaneous value of $V_{d o}(k)$ was determined by how much it deviates from its reference value. The voltage transfer ratio (voltage-gain) was compensated for according to the obtained deviation ratio. The real voltage-gain " $q(k)$ " can be obtained by multiplying the calculated deviation ratio by the voltagegain generated by the FLC system " $q^{l}(k)$ " at each sampling period. It can be defined mathematically as in (15)

$$
q(k)=q^{i}(k) \frac{V_{d o \_r e f}(k)}{V_{d o}(k)} .
$$

Also, the output of the hybrid compensation system was limited by a saturation block, because the value of voltagegain can be a maximum of $86.6 \%$ and cannot be negative.

As a result, the real voltage-gain value generated by the new hybrid compensation system was placed instead of the fixed voltage-gain $(q)$ in (7) and (9). The duty cycles of the bidirectional switches and the targeted output voltages were recalculated at each sampling period.

\section{RESUlts}

In this work, various simulations for the MC using the Optimum Amplitude Venturini Modulation (OAVM) method were performed to verify the usefulness and correctness of the new hybrid compensation method. First, MC model was developed by using Matlab \& Simulink, and, then, the proposed hybrid compensation system was applied to the developed model. The parameters used in this work are as follows. The amplitude $\left(V_{i}\right)$ and frequency $\left(f_{i}\right)$ of the input voltage are respectively $311 \mathrm{~V}$ and $50 \mathrm{~Hz}$, the output frequency $\left(f_{o}\right)$ is $30 \mathrm{~Hz}$, the resistance $(R)$ and inductance $(L)$ of the RL load are respectively $10 \Omega$ and $30 \mathrm{mH}$. The resistance $\left(R_{f}\right)$, inductance $\left(L_{f}\right)$, and capacitance $\left(C_{f}\right)$ values of the input filter are $0.1 \Omega, 3 \mathrm{mH}$, and $25 \mu \mathrm{F}$, respectively. The switching frequency $\left(f_{s}\right)$ is $10 \mathrm{kHz}$. The voltage-gain $(q)$ in the MC without compensation is 0.4 . The voltage-gain in the MC when compensated by the hybrid compensation system is variable continuously.

The modelled MC was subjected to the pure-sinusoidal input voltages between $0 \mathrm{~s}$ and $0.06 \mathrm{~s}$. It was subjected to the abnormal input voltages between $0.06 \mathrm{~s}$ and $0.2 \mathrm{~s}$. The used abnormal source voltages have $20 \%$ of the $3^{\text {rd }}$ and $10 \%$ of the $5^{\text {th }}$ harmonics.

In Figure 3, the waveforms of input voltages are given. The input voltages have highly harmonic contents between $0.06 \mathrm{~s}$ and $0.2 \mathrm{~s}$ as shown in Fig 3 .

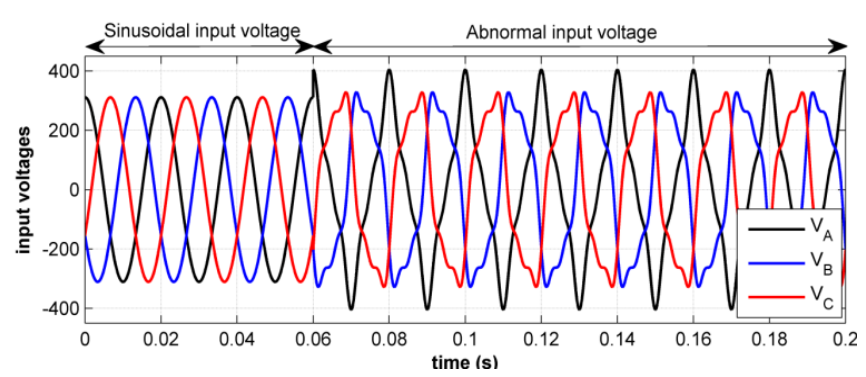

Fig. 3. Three-phase input voltages of the matrix converter.

Also, the waveform of the virtual DC line voltage $\left(V_{d o}\right)$ is constant until $0.06 \mathrm{~s}$ due to the sinusoidal source voltages. The waveform of $V_{d o}$ fluctuates depending on the disturbances in the input voltages during abnormal input voltage between $0.06 \mathrm{~s}$ and $0.2 \mathrm{~s}$ as illustrated in Fig. 4 .

In this study, the MC has been controlled by the conventional OAVM method without compensation between $0 \mathrm{~s}$ and $0.12 \mathrm{~s}$. This method was used a fixed voltage-gain value. Therefore, the waveform of the voltagegain is constant until $0.12 \mathrm{~s}$ as given in Fig. 5. The MC was controlled by using the proposed new hybrid compensation 
method between $0.12 \mathrm{~s}$ and $0.2 \mathrm{~s}$. It is clearly shown that the voltage-gain is not constant anymore during this time thanks to the proposed novel method under the non-sinusoidal input voltage conditions. While input voltages are pure sinusoidal until $0.06 \mathrm{~s}$, the output current space vector magnitude $\left(I_{d o}\right)$ has a constant value. When input voltage is non-sinusoidal, the output current space vector magnitude is a ripple as illustrated in Fig. 6.

This ripple means that the output current of the MC has highly harmonic contents. However, the output current space vector magnitude is constant between $0.12 \mathrm{~s}$ and $0.2 \mathrm{~s}$, because the harmonic contents of output current were eliminated by the proposed hybrid compensation system.

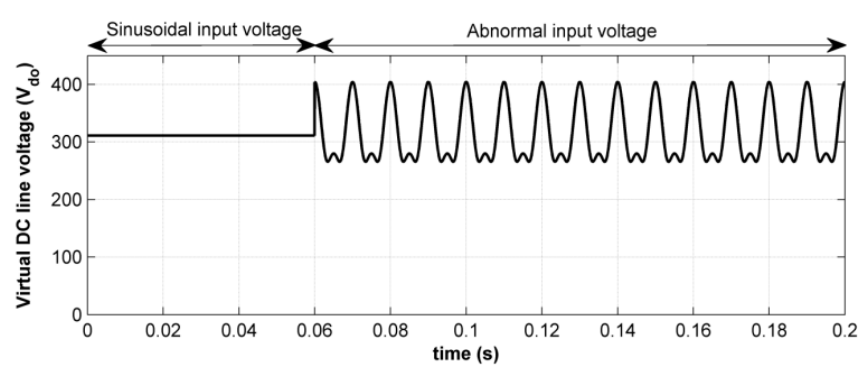

Fig. 4. Waveform of the virtual DC line voltage.

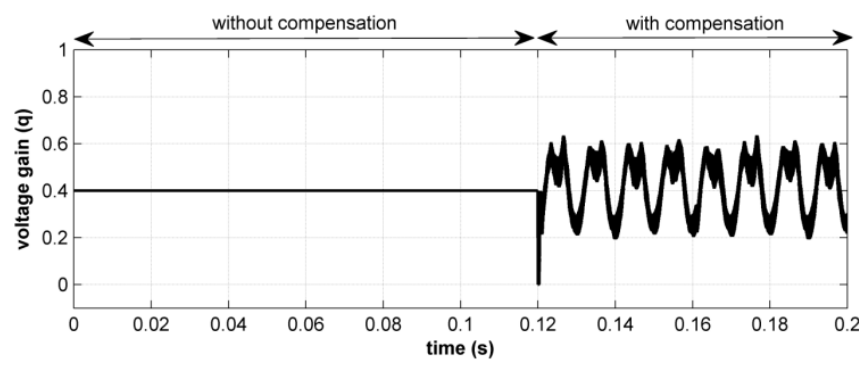

Fig. 5. Waveform of voltage-gain.

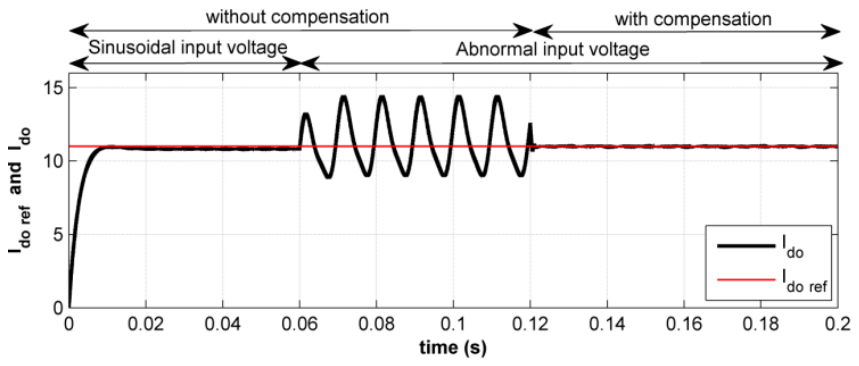

Fig. 6. The space-vector-magnitude waveform of the output current.

Figure 7 gives the 3-phase output currents of $\mathrm{MC}$ at $30 \mathrm{~Hz}$ - output frequency. These were presented for the MC under the three different conditions, which are fed by the sinusoidal source voltages controlled without compensation and controlled with compensation in the abnormal input voltages.

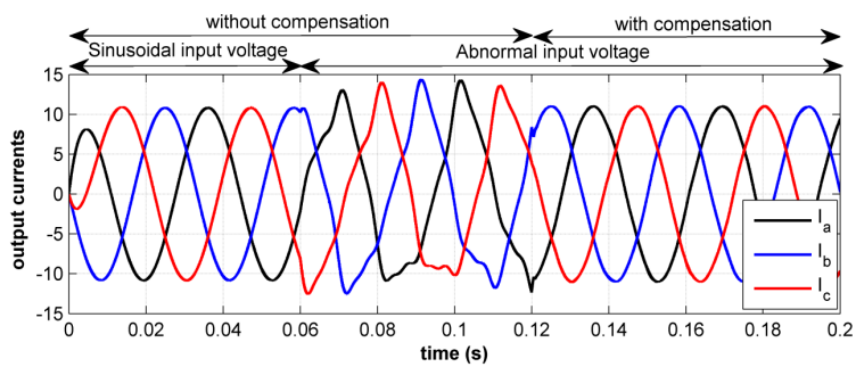

Fig. 7. Three-phase output currents.
It is understood that the output currents of the MC are also sinusoidal in the pure-sinusoidal source voltages. When the source voltage of the matrix converter is unbalanced, non-sinusoidal or with harmonics, the load current has also the low order harmonics and its waveform completely deviates from the sinusoidal shape. But, when the $\mathrm{MC}$ is compensated by the proposed novel technique under the same abnormal input voltage conditions, the distortions on the output currents can be sufficiently reduced. It is shown that the output currents of the MC with compensation are nearly pure-sinusoidal between $0.12 \mathrm{~s}$ and $0.2 \mathrm{~s}$.

The waveforms of the input phase voltages, the input currents drawn from the source and the output currents drawn by the load are given on the same axes in Fig. 8. As shown, while the frequencies of the input voltage and the current drawn from the source are $50 \mathrm{~Hz}$, the frequency of the output current is $30 \mathrm{~Hz}$.

Nonetheless, the power factor of the developed MC system is unity. The proposed compensation method has improved both the harmonic contents on the output side of the MC and that of the input side. As shown, both the output currents and the input currents are free of harmonics and their waveforms are nearly sinusoidal despite of the fact that the input voltages have distortions.

Figure 9 demonstrates the waveforms of the output phase voltages according to the neutral-point of the load, its averages and the output currents. It is shown that the output phase voltages have been synthesized by sequential piecewise sampling of the input waveforms at switching frequency $\left(f_{s}\right)$. While the input voltages don't have any harmonic contents (until $60 \mathrm{~ms}$ ), the averages of the output phase voltages have negligibly harmonic contents and their waveforms are sinusoidal. Nonetheless, the averages of the output phase voltages have highly harmonic contents between $60 \mathrm{~ms}$ and $120 \mathrm{~ms}$, because the MC has been subjected to the abnormal input voltage conditions during this time. If the MC is controlled by the proposed hybrid compensation method under the same abnormal input voltage conditions (after $120 \mathrm{~ms}$ ), the distortions of the phase voltages and output currents are eliminated.

The waveforms of the phase-to-phase voltages (the line voltages) and the averages of the phase-to-phase voltages are illustrated in Fig. 10. It is clearly shown that the averages of line voltages are non-sinusoidal waveforms for abnormal input voltages. However, the disturbance of the line voltage was satisfactorily reduced by the proposed compensation method.

Figure 11 shows the harmonics from $3^{\text {rd }}$ order to 11 th order and total harmonic distortions (THDs) of the phase-tophase voltages. While the input voltages are sinusoidal, the THD of the line voltage is $0.96 \%$. However, when the $20 \%$ 3rd harmonics and $10 \% 5^{\text {th }}$ harmonics are injected to the input voltages, the THDs of the output line voltages in the MC without compensation and with compensation are $32.45 \%$ and $4.16 \%$, respectively.

These results proved that the hybrid compensation controller has significantly reduced the disturbance of phase-to-phase voltages on the load of the MC in nonsinusoidal input voltages.

Figure 12 shows harmonics from $3^{\text {rd }}$ to $11^{\text {th }}$ and total harmonic distortions (THDs) of the output currents. 


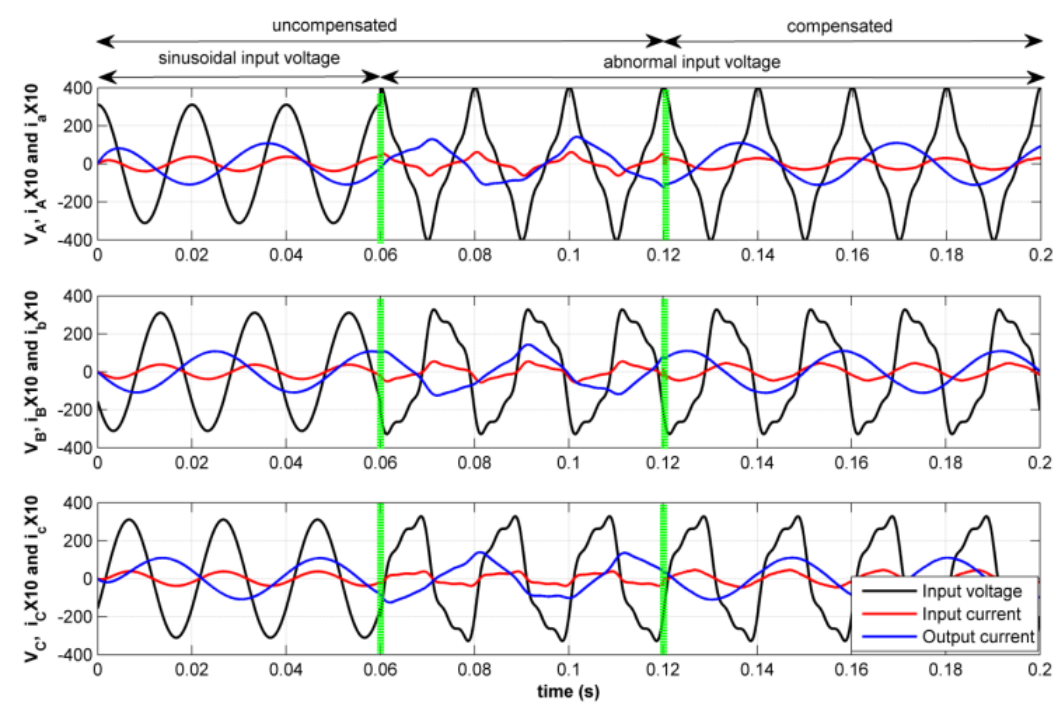

Fig. 8. The three- phase output and input currents and the three-phase input voltages.
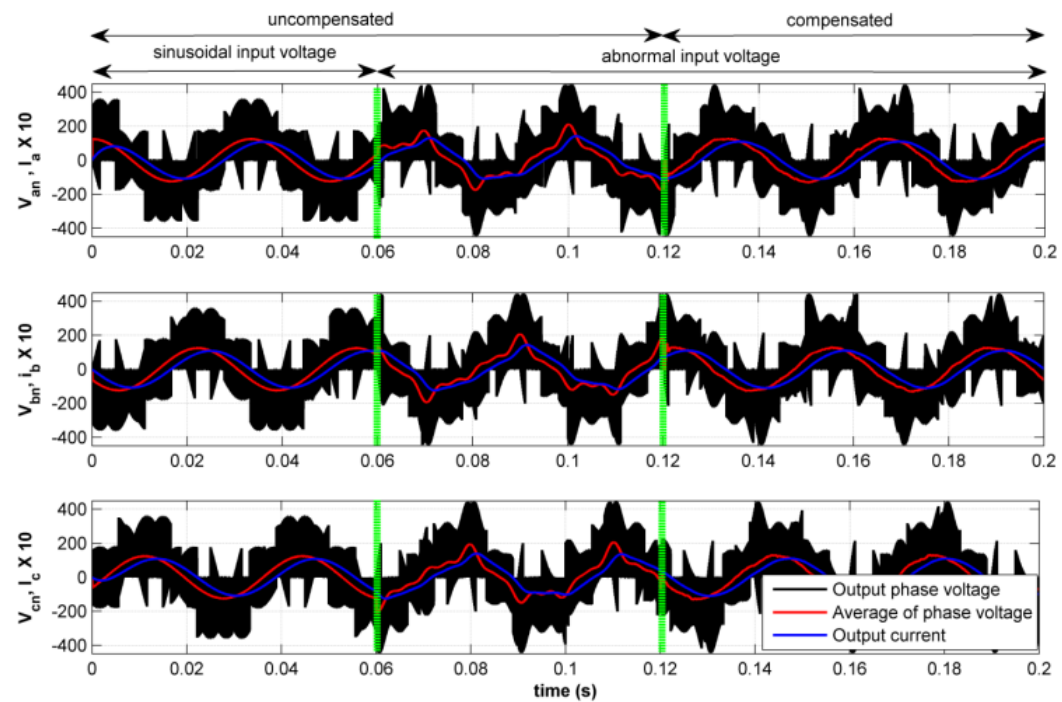

Fig. 9. The output phase voltages with respect to the neutral of load, the averages of phase voltages, and the output currents.
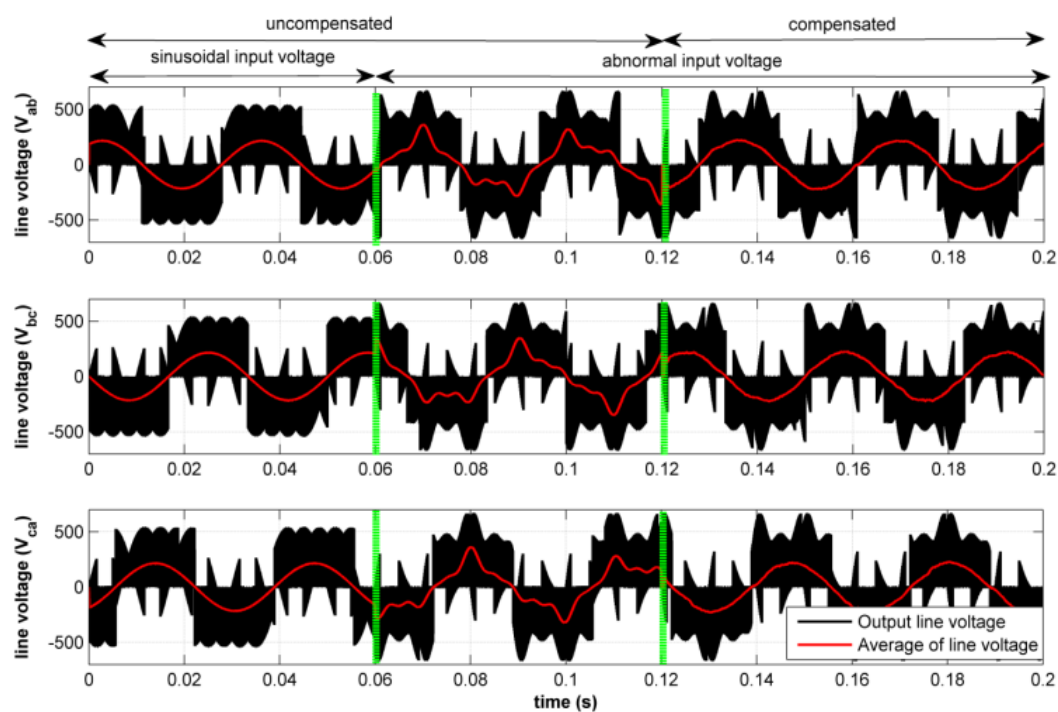

Fig. 10. The output line voltages, the averages of the line voltages.

While the input voltages are sinusoidal, the THD of the output current is $0.64 \%$. While the input voltages are nonsinusoidal and abnormal, the THDs of the output currents in the $\mathrm{MC}$ without compensation and with compensation are
$16.48 \%$ and $2.09 \%$, respectively. It is understood that the proposed hybrid compensation method reduced not only THDs on the output line voltages of the MC, but also that of the output currents. 


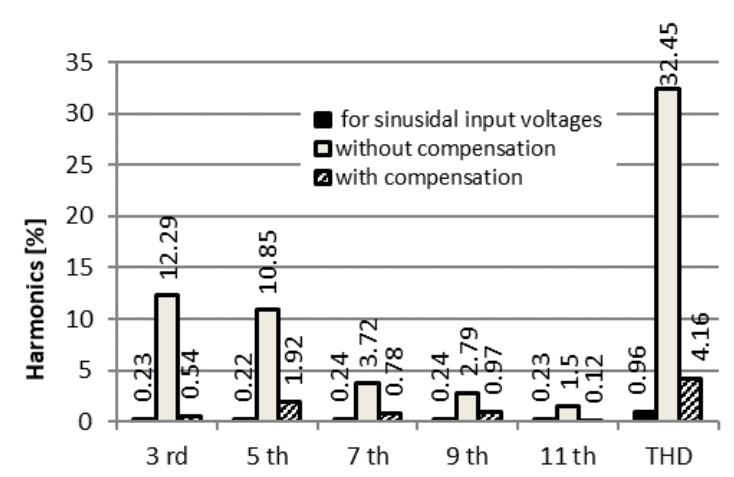

Fig. 11. The harmonics and THDs of the output line voltages.

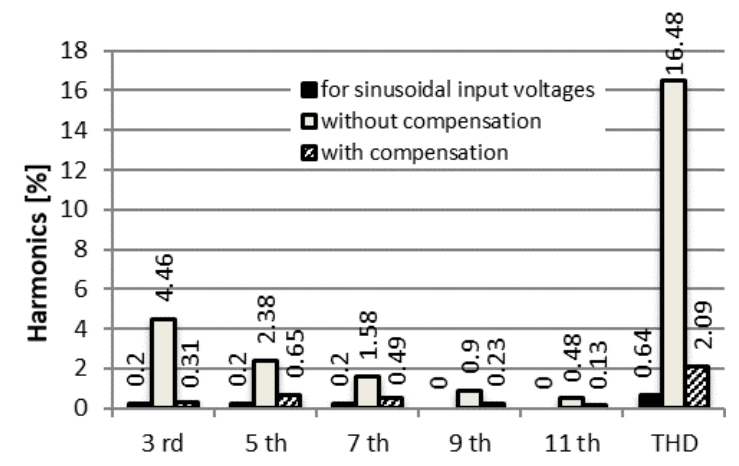

Fig. 12. The harmonics and THDs of the output currents.

\section{CONCLUSIONS}

Since the MC makes a single-stage conversion, any disturbance in the power grid reflects to output voltages, output currents, and input currents under the distorted input voltage conditions. A novel hybrid compensation method, which has both feedforward and feedback, is suggested to improve the output voltages, output currents, and input currents of the MC. The proposed hybrid controller satisfactorily minimizes harmonic contents and THDs in the input currents, output currents, and output voltages in the case of abnormal input voltages.

Also, the suggested novel technique not only eliminates the THD and harmonic contents of the output, but also provides limitation of the over-current and control of the load current. The presented results clearly prove that the suggested new hybrid compensation approach is an effective method to eliminate the undesired harmonics and to reduce the THD of the MC.

\section{CONFLICTS OF INTEREST}

The authors declare that they have no conflicts of interest.

\section{REFERENCES}

[1] P. W. Wheeler, J. Rodriguez, J. C. Clare, L. Empringham, and A. Weinstein, "Matrix converters: A technology review", IEEE Transactions on industrial electronics, vol. 49, no. 2, pp. 276-288, 2002. DOI: $10.1109 / 41.993260$.

[2] J. Rodriguez, M. Rivera, J. W. Kolar, and P. W. Wheeler, "A review of control and modulation methods for matrix converters", IEEE transactions on industrial electronics, vol. 59, no. 1, pp. 58-70, 2012. DOI: 10.1109/TIE.2011.2165310.

[3] H. Karaca and R. Akkaya, "Modelling and simulation of matrix converter under distorted input voltage conditions", Simulation Modelling Practice and Theory, vol. 19, no. 2, pp. 673-684, 2011. DOI: 10.1016/j.simpat.2010.09.005.

[4] R. L. Iglesias, R. L. Arantegui, and M. A. Alonso, "Power electronics evolution in wind turbines-A market-based analysis", Renewable and Sustainable Energy Reviews, vol. 15, no. 9, pp. 4982-4993, 2011. DOI: 10.1016/j.rser.2011.07.056.

[5] H. Karaca, R. Akkaya, and H. Dogan, "A novel compensation method based on fuzzy logic control for matrix converter under distorted input voltage conditions", in Proc. of 2008 18th International Conference on Electrical Machines, 2008, pp. 1-5. DOI: 10.1109/ICELMACH.2008.4800091.

[6] X. Wang, H. Lin, H. She, and B. Feng, "A research on space vector modulation strategy for matrix converter under abnormal inputvoltage conditions", IEEE Transactions on Industrial Electronics, vol. 59, no. 1, pp. 93-104, 2012. DOI: 10.1109/TIE.2011.2157288.

[7] X. Wang, H. Lin, H. She, and B. Feng, "Research on matrix converter control strategy under abnormal input voltages", in Proc. of. IECON 2010 - 36th Annual Conference on IEEE Industrial Electronics Society, 2010, pp. 680-685. DOI: 10.1109/IECON.2010.5675232.

[8] K. Park, K.-B. Lee, and F. Blaabjerg, "Improving output performance of a Z-source sparse matrix converter under unbalanced input-voltage conditions", IEEE Trans. Power Electron., vol. 27, no. 4, pp. 20432054, 2012. DOI: 10.1109/TPEL.2011.2170709.

[9] K. Park, E.-S. Lee, and K.-B. Lee, "A Z-source sparse matrix converter with a fuzzy logic controller based compensation method under abnormal input voltage conditions", in Proc. of 2010 IEEE International Symposium on Industrial Electronics, 2010, pp. 614619. DOI: 10.1109/ISIE.2010.5637169.

[10] D. Casadei, G. Serra, A. Tani, and L. Zarri, "Optimal use of zero vectors for minimizing the output current distortion in matrix converters", IEEE Transactions on Industrial Electronics, vol. 56, no. 2, pp. 326-336, 2009. DOI: 10.1109/TIE.2008.2007557.

[11] J.-K. Kang, H. Hara, A. M. Hava, E. Yamamoto, E. Watanabe, and T. Kume, "The matrix converter drive performance under abnormal input voltage conditions", IEEE transactions on power electronics, vol. 17, no. 5, pp. 721-730, 2002. DOI: 10.1109/TPEL.2002.802191.

[12] F. Blaabjerg, D. Casadei, C. Klumpner, and M. Matteini, "Comparison of two current modulation strategies for matrix converters under unbalanced input voltage conditions", IEEE Transactions on Industrial Electronics, vol. 49, no. 2, pp. 289-296, 2002. DOI: 10.1109/41.993261.

[13] E. Babaei, S. H. Hosseini, and G. B. Gharehpetian, "Reduction of THD and low order harmonics with symmetrical output current for single-phase ac/ac matrix converters", International journal of electrical power \& energy systems, vol. 32, no. 3, pp. 225-235, 2010. DOI: 10.1016/j.ijepes.2009.07.004.

[14] C. Ponmani and M. Rajaram, "Compensation strategy of matrix converter fed induction motor drive under input voltage and load disturbances using internal model control", International Journal of Electrical Power \& Energy Systems, vol. 44, no. 1, pp. 43-51, 2013. DOI: 10.1016/j.ijepes.2012.07.031.

[15] R. Cárdenas, R. Peña, P. Wheeler, J. Clare, and C. Juri, "Control of a matrix converter for the operation of autonomous systems", Renewable Energy, vol. 43, pp. 343-353, 2012. DOI: 10.1016/j.renene.2011.11.052.

[16] R. Cárdenas, C. Juri, R. Peña, P. Wheeler, and J. Clare, "The application of resonant controllers to four-leg matrix converters feeding unbalanced or nonlinear loads", IEEE Transactions on Power Electronics, vol. 27, no. 3, pp. 1120-1129, 2012. DOI: 10.1109/TPEL.2011.2128889.

[17] J. Zhang, L. Li, and D. G. Dorrell, "Control and applications of direct matrix converters: A review", Chinese Journal of Electrical Engineering, vol. 4, no. 2, pp. 18-27, 2018. DOI: 10.23919/CJEE.2018.8409346

[18] J. Rodriguez, E. Silva, F. Blaabjerg, P. Wheeler, J. Clare, and J. Pontt, "Matrix converter controlled with the direct transfer function approach: analysis, modelling and simulation", International Journal of Electronics, vol. 92, no. 2, pp. 63-85, 2005. DOI: $10.1080 / 00207210512331337686$.

[19] M. Venturini, "A new sine wave in sine wave out, conversion technique which eliminates reactive elements", in Proc. of Powercon 7, 1980.

[20] A. Alesina and M. G. Venturini, "Analysis and design of optimumamplitude nine-switch direct AC-AC converters", IEEE Transactions on Power Electronics, vol. 4, no. 1, pp. 101-112, 1989. DOI: $10.1109 / 63.21879$.

[21] H. Karaca and R. Akkaya, "Control of Venturini method based matrix converter in input voltage variations", in Proc. of the International Multi Conference of Engineers and Computer Scientists IMECS, Hong Kong, 2009, vol. 2.

[22] N. Hinov, B. Gilev,T. Hranov, "Model-Based Optimization of an LLC-Resonant DC-DC Converter", Electronics, vol. 8, no. 7, article no. 799, 2019. DOI: 10.3390/electronics8070799. 